\title{
THE EFFICACY OF DEXMEDETOMIDINE, PROPOFOL AND KETAMINE IN ELDERLY PATIENT UNDERGOING SPINAL ANESTHESIA FOR PREVENTION OF POST-OPERATIVE DELIRIUM
}

\author{
By \\ Yousry Abd El-Salam Kandil \\ Department of Anesthesia and ICU, Faculty of Medicine (Damietta), Al-Azhar University \\ E-mail: yousrykandil@yahoo.com
}

\begin{abstract}
Background: Post-operative delirium in elderly patient needed to operative procedures is a risk factor to deteriorate outcomes of this patient. The prevalence of post-operative delirium ranges from $10 \%$ to $37 \%$ in elderly patient undergoing anesthesia especially in those receiving general anesthesia and is related to poor function recovery, increasing length of stay in hospital, increasing the frequency of early post-operative cognitive dysfunction (POCD) and morbidity.
\end{abstract}

Objective: to compare the efficacy of dexmedetomidine, propofol, and ketamine in elderly patients undergoing spinal anesthesia for prevention of post-operative delirium.

Patients and Methods: A prospective, randomized controlled study was conducted on 60 patients of both genders, aged $60-75$ years, with ASA physical status I, II and III, scheduled for elective surgery in the lower abdomen and lower limb undergoing spinal anesthesia from March 2019 to March 2020 at Al-Azhar University Hospital (Damietta). They were randomized into three equal groups: Group I received premedication dexmedetomidine $(1 \mu \mathrm{g} / \mathrm{kg})$, given slowly intravenously over 10 minutes, Group II received intravenous propofol $(0.5 \mathrm{mg} / \mathrm{kg})$, and Group III received intravenous ketamine $(0.5 \mathrm{mg} . / \mathrm{kg})$. The primary endpoint was the incidence of post-operative delirium (POD), which was assessed using confusion assessment method (CAM) from the first postoperative day to the third postoperative day.

Results: Dexmedetomidine group has a lower incidence of postoperative delirium than propofol group without statistical significant difference, while ketamine group has high incidence of postoperative delirium with statistical significant difference than other two groups numbering from statistics.

Conclusion: Dexmedetomidine group was associated with a lower incidence of POD than propofol group, while ketamine group was associated with a high incidence of POD than other two groups and thus resulting in better short recovery, short hospital stay, and thus decreasing health care cost and morbidity.

Key words: Dexmedetomidine, Propofol, Ketamine, Delirium.

\section{INTRODUCTION}

Delirium is a neuropsychiatric disorder characterized by a sudden onset of altered and fluctuating level of consciousness, inattention, and disorganized thinking, post-operative delirium (POD) is extremely variable and ranged from $0 \%$ to $73.5 \%$ (average $36.8 \%$ ) (Inouye et al., 2014). Other study stated that the prevalence of POD ranges from $16 \%$ to $62 \%$ with higher incidences in older patients, patients with preexisting cognitive impairment, after cardiac 
surgery, and after emergency surgery, especially surgery for hip fracture (Rudolph et al., 2010). Preoperative use of benzodiazepines, opioids, and alcohol can cause a poor functional recovery. increase length of stay in hospital, increase frequency of early POCD and mortality, spinal anesthesia was preferred than general anesthesia for elderly patient due to avoidance of general anesthetic drugs especially opioids which may be related to POD, also spinal anesthesia facilitates the restoration of oral intake and functional recovery (Zhang et al., 2013).

Postoperative delirium is prevalent, poorly understood, and often missed with routine clinical care, since there is no single treatment known for postoperative delirium. Much attention is directed towards prevention of delirium in populations at risk. Screening for risk factors of postoperative delirium is the first step in prevention (Bilotta et al., 2013).

POD impair functional recovery, prolong the length of hospital stay, and increase post-operative complications (Gleason et al., 2015).

The pathophysiology of delirium remains to be not fully understood: There is a suggestion that a deficiency of acetylcholine and dopamine excess may be the cause of delirium (Maldonado, 2013). Other suggestion that surgical stress produces pro inflammatory cascade causing brain edema and hypo perfusion. It increases the risk of gaseous, fat, or lipid cerebral micro emboli, causing acute and prolonged cognitive dysfunction. (Hirsch et al., 2015). Other suggestion that the disturbance of sleep-wake cycle is responsible for delirium, melatonin metabolism and its derivatives. Objective measurements were suggested, but their causal relation is unclear (De Rooj and Van Munster, 2013).

Intraoperative sedation has the following advantages of avoiding postural discomfort, preventing intraoperative recall, and reducing sympathetic and para sympathetic reflexes. Several studies recommend another sedative drug. Dexmedetomidine could be potentially helped in reducing occurrence of POD (Sieber et al., 2010).

The present work aimed to compare the efficacy of dexmedetomidine, propofol, and ketamine in elderly patients undergoing spinal anesthesia for prevention of post-operative delirium.

\section{MATERIALS AND METHODS}

After getting approval of local Ethics Committee and written informed consents from 60 patients was admitted to AlAzhar university hospital (Damietta) from March 2019 to March 2020. This prospective blind randomized study was conducted on 60 patients of both genders, aged $60-75$ years, with American Society of Anesthesiologist (ASA) physical status I, II and III, scheduled for elective surgery in the lower abdomen and lower limb undergoing spinal anesthesia.

\section{Exclusion criteria:}

Asthmatic patient, cardiovascular disease, severe renal, hepatic or endocrinal dysfunction, patients with known drug hypersensitivity, patients with mental disorder or those receiving antidepressant drugs, and those who refused giving consents. 
All the patients underwent preanesthetic evaluation with history, general and systemic examination and review of biochemical investigations before enrolment in the study.

They were randomized into three equal groups: Group I received premedication dexmedetomidine $(1 \mu \mathrm{g} / \mathrm{kg})$, given slowly intravenously over $10 \mathrm{~min}$, Group II received intravenous propofol $(0.5$ $\mathrm{mg} / \mathrm{kg}$ ), and Group III received intravenous ketamine $(0.5 \mathrm{mg} / \mathrm{kg})$.

In the operative theater, monitors were attached, and baseline heart rate, electrocardiogram (ECG), systemic arterial blood pressure, oxygen saturation (SpO2) and end-tidal carbon dioxide concentration were recorded. A crystalloid intravenous infusion of 6 to $8 \mathrm{ml} / \mathrm{kg}$ was started. All of the patients were assigned to receive spinal anesthesia.

Hemodynamic was recorded such as mean arterial blood pressure (MAP), heart rate (HR), oxygen saturation each 15 minutes interval, the primary endpoint was the occurrence of POD. Assessment of delirium was assessed using CAM from the first postoperative day to the third postoperative day. Identification of POD can be assessed by confusion assessment method (CAM algorithm) which is sensitive (94\%-100\%), specific (90-95), reliable, and easy to use, it included a four step the first: an acute onset of changes in the mental status, the second is in attention, the third is disorganized thinking, and lastly an altered level of consciousness. If both features (1) and (2) were present plus either feature (3) or (4), patients were rendered either CAM positive (delirium present) or CAM negative (delirium absent) CAM was done according to Inouye et al. (2014). Postoperative pain was assessed by visual analogue score (VAS), and of ambulation which represented by the time from end of surgery until ambulation. Also discharge time was recorded (time from surgery until discharge); postoperative complication also was recorded such as acute renal failure, pulmonary infection, myocardial ischemia, new dysrhythmia and wound infection.

Delirium, if occurred, was treated by IV haloperidol in the increments of 1 to 5 $\mathrm{mg}$, repeated every 30 to $60 \mathrm{~min}$ as needed, (Intraoperative hypotension if blood pressure decrease $>30 \%$ in systolic blood pressure from preoperative values and/or systolic blood pressure $<90 \mathrm{mmHg}$. If observed, these conditions were immediately treated with an infusion of ephedrine. Intraoperative bradycardia if heart rate $<50$ beats per minute, and treated with atropine $(0.01 \mathrm{mg} / \mathrm{kg})$. Confusion assessment method (CAM) was done according to (Inoye et al. (2014).

\section{Statistical analysis:}

Numerical data were explored for normality by checking the distribution of data and using tests of normality (Kolmogorov-Smirnov and Shapiro-Wilk tests). All data showed normal (parametric) distribution except for pain (VAS) scores data which showed nonnormal (non-parametric) distribution. Data were presented as mean and standard deviation (SD) values. For parametric data, one-way ANOVA test was used for comparisons between the groups. Bonferroni's post-hoc test was used for pair-wise comparisons when ANOVA test is significant. For non-parametric data, Kruskal-Wallis test was used to compare 
between the three groups. Friedman's test was used to study the changes by time within each group. Dunn's test was used for pair-wise comparisons. Qualitative data were presented as frequencies and percentages. Chi-square test was used for comparisons between the groups. The significance level was set at $\mathrm{P} \leq 0.05$. Statistical analysis was performed with IBM SPSS Statistics for Windows, Version 23.0. Armonk, NY: IBM Corp.

\section{RESULTS}

The present study included 3 groups of patients (a total of 60 participants), the first group: included 20 participants (Dexmedetomidine group), the second group: included 20 participants (Propofol group) and the third group: included 20 participants (Ketamine group) with the same inclusion and exclusion criteria.

No statistically significant difference between studied groups according to demographic data regarding age, sex, ASA and duration of anesthesia, (Table 1).

Table (1): Comparison between groups according to demographic data

\begin{tabular}{|c|c|c|c|c|}
\hline Variables Groups & $\begin{array}{c}\text { Dexmed } \\
(n=20)\end{array}$ & $\begin{array}{l}\text { Propofol } \\
(\mathbf{n}=20)\end{array}$ & $\begin{array}{c}\text { Ketamine } \\
(\mathbf{n}=\mathbf{2 0})\end{array}$ & p-value \\
\hline Age (years) & $64.55 \pm 3.91$ & $62.86 \pm 3.26$ & $63.73 \pm 3.12$ & $>0.05$ \\
\hline \multicolumn{5}{|l|}{ Sex } \\
\hline Male & $12(60.0 \%)$ & $11(55.0 \%)$ & $13(65.0 \%)$ & \multirow{2}{*}{$>0.05$} \\
\hline Female & $8(40.0 \%)$ & $9(45.0 \%)$ & $7(35.0 \%)$ & \\
\hline \multicolumn{5}{|l|}{ ASA Class } \\
\hline I & $5(25.0 \%)$ & $3(15.0 \%)$ & $6(30.0 \%)$ & \multirow{3}{*}{$>0.05$} \\
\hline II & $7(35.0 \%)$ & $5(25.0 \%)$ & $6(30.0 \%)$ & \\
\hline III & $8(40.0 \%)$ & $12(60.0 \%)$ & $8(40.0 \%)$ & \\
\hline Duration of anesthesia (min) & $79.20 \pm 3.27$ & $80.19 \pm 3.31$ & $79.70 \pm 3.29$ & $>0.05$ \\
\hline
\end{tabular}

Using: F-One Way Analysis of Variance; x2: Chi-square test

There were no statistical significant differences between studied groups in oxygen saturation. Dexmeditomidine group slightly decreased in heart rate and MAP than propofol group, but without
Statistical significant difference, while ketamine group there were increase in heart rate and MAP with statistical significant difference than other two groups (Table 2). 
THE EFFICACY OF DEXMEDETOMIDINE, PROPOFOL AND...

Table (2): Comparison between groups according to hemodynamic data

\begin{tabular}{|c|c|c|c|c|}
\hline$\overbrace{\text { Hemodynamics }}^{\text {Groups }}$ & $\begin{array}{c}\text { Dexmed } \\
(\mathbf{n}=\mathbf{2 0})\end{array}$ & $\begin{array}{c}\text { Propofol } \\
(\mathbf{n}=20)\end{array}$ & $\underset{(\mathbf{n}=20)}{\text { Ketamine }}$ & P-value \\
\hline \multicolumn{5}{|l|}{ Heart rate } \\
\hline Basal & $73.68 \pm 3.50$ & $71.81 \pm 2.35$ & $71.91 \pm 2.55$ & $>0.05$ \\
\hline At $15 \mathrm{~min}$ & $68.18 \pm 4.17$ & $70.85 \pm 2.29^{\mathrm{a}}$ & $70.95 \pm 2.37^{\mathrm{a}}$ & $0.001 *$ \\
\hline At $30 \mathrm{~min}$ & $67.27 \pm 4.13$ & $70.65 \pm 1.75^{\mathrm{a}}$ & $70.70 \pm 1.96^{\mathrm{a}}$ & $<0.001 * *$ \\
\hline At $45 \mathrm{~min}$ & $69.34 \pm 3.48$ & $70.70 \pm 1.54$ & $70.70 \pm 1.88$ & $>0.05$ \\
\hline At $60 \mathrm{~min}$ & $69.08 \pm 3.45$ & $70.40 \pm 1.42$ & $70.55 \pm 1.74$ & $>0.05$ \\
\hline At end & $69.03 \pm 3.35$ & $70.25 \pm 1.32$ & $70.40 \pm 1.80$ & $>0.05$ \\
\hline \multicolumn{5}{|l|}{ MAP } \\
\hline Basal & $89.33 \pm 2.45$ & $89.28 \pm 2.45$ & $90.04 \pm 2.00$ & $>0.05$ \\
\hline At $15 \mathrm{~min}$ & $81.76 \pm 3.73$ & $84.74 \pm 2.19^{\mathrm{a}}$ & $85.35 \pm 1.89^{\mathrm{a}}$ & $<0.001 * *$ \\
\hline At $30 \mathrm{~min}$ & $81.76 \pm 3.85$ & $84.59 \pm 2.37^{\mathrm{a}}$ & $84.79 \pm 1.32^{\mathrm{a}}$ & $<0.001 * *$ \\
\hline At $45 \mathrm{~min}$ & $85.14 \pm 2.09$ & $85.04 \pm 1.59$ & $85.60 \pm 2.04$ & $>0.05$ \\
\hline At $60 \mathrm{~min}$ & $85.80 \pm 1.89$ & $85.35 \pm 1.62$ & $85.19 \pm 2.07$ & $>0.05$ \\
\hline At end & $86.51 \pm 2.43$ & $85.75 \pm 1.38$ & $86.00 \pm 1.94$ & $>0.05$ \\
\hline \multicolumn{5}{|l|}{ SPO2 } \\
\hline Basal & $98.40 \pm 0.80$ & $98.05 \pm 0.68$ & $98.45 \pm 0.67$ & $>0.05$ \\
\hline At $15 \mathrm{~min}$ & $98.35 \pm 0.85$ & $98.25 \pm 0.81$ & $98.25 \pm 0.87$ & $>0.05$ \\
\hline At $30 \mathrm{~min}$ & $98.30 \pm 0.78$ & $98.60 \pm 0.68$ & $98.30 \pm 0.76$ & $>0.05$ \\
\hline At $45 \mathrm{~min}$ & $98.30 \pm 0.83$ & $98.40 \pm 0.92$ & $98.15 \pm 0.75$ & $>0.05$ \\
\hline At $60 \mathrm{~min}$ & $98.15 \pm 0.75$ & $98.20 \pm 0.71$ & $98.05 \pm 0.68$ & $>0.05$ \\
\hline At end & $98.25 \pm 0.74$ & $98.25 \pm 0.75$ & $98.35 \pm 0.78$ & $>0.05$ \\
\hline
\end{tabular}

Using: F-One Way Analysis of Variance

Post HOC: a: significant difference with Dexmed

As regard POD dexmedetomidine group has lower incidence than propofol group without statistical significant difference, while ketamine group showed high incidence of POD with statistical significant difference than other two groups. As regard post-operative pain, there were no statistical significant differences between studied groups at the end of surgery. Also, there were no statistical significant differences between studied groups during three post-operative days. Also, there were no statistical significant difference between studied groups as regard time of ambulation and time of discharge (Table 3). 
Table (3): Comparison between groups according to Delirium, VAS score, time of amputation and time of discharge

\begin{tabular}{|c|c|c|c|c|}
\hline $\begin{array}{ll}\text { Variables } & \text { Groups } \\
\end{array}$ & $\begin{array}{c}\text { Dexmed } \\
(n=20)\end{array}$ & $\begin{array}{c}\text { Propofol } \\
(\mathbf{n}=20)\end{array}$ & $\begin{array}{c}\text { Ketamine } \\
(\mathbf{n}=\mathbf{2 0})\end{array}$ & p-value \\
\hline \multicolumn{5}{|l|}{ Delirium } \\
\hline At end of operation & $1(5.0 \%)$ & $2(10.0 \%)$ & $6(30.0 \%)$ & $>0.05$ \\
\hline Day 1 & $1(5.0 \%)$ & $2(10.0 \%)$ & $6(30.0 \%)$ & $>0.05$ \\
\hline Day 2 & $0(0.0 \%)$ & $1(5.0 \%)$ & $4(20.0 \%)$ & $0.031^{*}$ \\
\hline Day 3 & $0(0.0 \%)$ & $0(0.0 \%)$ & $3(15.0 \%)$ & $>0.05$ \\
\hline \multicolumn{5}{|l|}{ VAS score } \\
\hline At end of operation & $1.71 \pm 1.23$ & $1.82 \pm 1.28$ & $2.18 \pm 1.39^{\mathrm{ab}}$ & $0.028^{*}$ \\
\hline Day 1 & $1.82 \pm 1.39$ & $1.90 \pm 0.86$ & $2.25 \pm 1.50^{\mathrm{ab}}$ & $0.024 *$ \\
\hline Day 2 & $1.71 \pm 0.75$ & $1.93 \pm 1.39$ & $2.35 \pm 1.18^{\mathrm{ab}}$ & $0.012 *$ \\
\hline Day 3 & $1.93 \pm 2.03$ & $2.03 \pm 1.71$ & $2.57 \pm 0.32^{\mathrm{ab}}$ & $0.021 *$ \\
\hline Time of amputation & $1.50 \pm 0.21$ & $1.82 \pm 0.32$ & $2.03 \pm 0.43$ & $>0.05$ \\
\hline Time of discharge & $5.11 \pm 2.14$ & $5.21 \pm 5.35$ & $5.76 \pm 0.32^{\mathrm{ab}}$ & $0.031 *$ \\
\hline
\end{tabular}

Using: F-One Way Analysis of Variance; H-Kruskal Wallis test; x2: Chi-square test

Post HOC: a: significant difference with Dexmed; b: Significant difference with Propofol

No post-operative complication occurred such as acute renal failure,

\section{DISCUSSION}

Delirium was considered as a significant complication in postoperative patients, with a higher incidence among elderly patients; however, delirium is still frequently not appropriately assessed and managed, and thus the morbidity and mortality increased frequently. So, it must be diagnosed and treated, and must be prevented in the perioperative period (Inouye et al., 2014).

Delirium was identified by Confusion Assessment Method (CAM), which is a scoring system for delirium and has been suggested to have predictive validity for accurate diagnosis of delirium (Avidan et al., 2017).

With the application of regional anesthesia (RA), the risk of POD can be reduced or avoided. It continues to be debated whether RA reduces the incidence pulmonary infection, myocardial ischemia, or new dysrhythmia.

of POD compared with general anesthesia (GA) (Lee and Park, 2010).

Dexmedetomidine (an $\alpha 2$ adrenoceptor agonist), it produces a sedative effect at low doses that mimics natural stage 2 nonrapid eye movement sleep and the patients remain drowsy but are cooperative and arousal (Adam et al ., 2013).

Ketamine, a phencyclidine analogue and a non-competitive antagonist of $\mathrm{N}$ methyl-d-aspartate (NMDA) receptors, it is used as intravenous anesthetic and produces dissociative anesthetic state, also has advantage of preservation of air way reflexes, at lower doses there's no respiratory depression and has sedative and amnestic effect (Bazin et al., 2010).

In the present study, there were no Statistical significant difference between studied groups, as regard to age, sex and ASA classification and this in accordance to $M e i$ et al. (2018) where they reported that there was no statistical significant 
difference in age and sex when they are comparing intraoperative sedation of dexmedetomidin with propofol in elderly patients undergoing hip arthroplasty.

As regard to oxygen saturation there were no statistical significant difference between studied groups, and this result was in concomitant with Gupta et al. (2011) where they recorded that there was no respiratory depression and was not seen in any of the patients intra operatively and none of patients had shown fall in oxygen saturation, no patient required a nasopharyngeal or oropharyngeal airway to maintain the patency of airway.

As regard to hemodynamic, Dexmedetomidin. group is slightly decrease in heart rate and MAP than propofol group but without statistical significant difference, while ketamine group there were increase in heart rate and MAP with Statistical significant difference than other two groups.

This is in accordance with Xudong et al. (2015) in which he reported that Patients' HR and MAP were lower in the dexmedetomidine group than in the control group and is caused by the inhibitory effect of dexmedetomidin on the sympathetic nervous system. Also, Hao et al. (2019) reported that there were decrease in mean blood pressure and heart rate after administration of dexmedetomidin during the intra operative period.

$\mathrm{Su}$ et al. (2016) demonsrated that Dexmedetomidine is selectively binding to postsynaptic $\alpha 2$ adrenergic receptor and inhibits nervous impulse from sympathetic neurons in anterior horn cells of the spinal cord and reduces systemic sympathetic nervous tension, its sedative effect is similar to physiological sleep, with less respiratory depression, and decrease of HR or blood pressure.

In our study, there were lower incidences of POD in dexmedetomidine group than propofol group without statistical significant difference, while ketamine group there were high incidence of POD with statistical significant difference than other two groups, and this was in accordance to Hao et al. (2019) who found that perioperative dexmedetomidin. reduces the incidence of POD in elderly patient after non cardiac surgery in which he reported the incidence of agitation was lower in the dexmedetomidine group than in the control group (10.3\% [4 of 39] vs. $30 \%$ [12 of 40], respectively; $(\mathrm{P}=.029)$. and this data suggest that dexmedetomidine is effective in decreasing agitation after admission to the PACU. Also, Esmaoglu et al. (2010) recommended that in his study dexmedetomidine should be used for sedation to reduce the duration of delirium, it is widely used because it can provide a natural sleep-like state without causing respiratory depression and easily arousable.

In our study, dexmedetomedine has lower incidence of POD than propofol and this are decreasing the morbidity and result in better short recovery, and short hospital stay and thus decrease health care cost. This result in agreement with $M e i$ et al. (2018) who concluded that using dexmetedomidine as a supplementary to peripheral nerve block can reduces POD, and thus resulting in better outcomes, short hospital stay, and early recovery after hip arthroplasty. 
Su et al. (2016) reported that sedation with Dexmedetomidine was associated with a lower incidence of POD compared with sedation with propofol. Sedation with dexmedetomidine also facilitates patients to be out of bed and discharged early after surgery. Although dexmedetomidine has effectiveness to prevent delirium, its use remains controversial, moreover supporting clinical data from well controlled studies regarding the optimal timing and dosing schedule of dexmedetomidine has yet to be established.

In contrast to our study, Xudog et al. (2015) found that there were no change overall incidence of agitation after free flap surgery, and does not prevent delirium within 5 days post-operative. This disagreement may be due to optimal timing and dosing scheduled of dexmedetomidin or due to the duration of operation.

Ketamine and dexmedetomidine have been investigated by Mizrak et al. (2010) to explore their ability to reduce the incidence of POD. They demonstrated that dexmedetomidine may reduce the incidence of POD in elderly patients when compared to propofol.

Avidan et al. (2017) found that the incidences of POD $17.65 \%$ of patients using the $0.5 \mathrm{mg} / \mathrm{kg}$ ketamine were diagnosed with delirium after non cardiac surgery. Also, similar result was reported when Pan et al. (2019) found that the incidence of POD was $14.5 \%$ of patient undergoing lumbar spine surgery in elderly patients.

\section{CONCLUSION}

Dexmetedomidine Group is associated with a lower incidence of POD than propofol group, while ketamine group is associated with a high incidence of POD than other two groups and thus resulting in better short recovery and short hospital stay and thus decreasing health care cost and morbidity.

\section{REFERENCES}

1. Adam S, Bobby N, Dominic C and Usha R. (2013): Dexmedetomidine for Neurosurgical procdure. Curr Anesthesiol., Rep 3 (8):205209.

2. Avidan MS, Maybrier HR, Abdallah AB, Jacobsohn E, Vlisides PE and Pryor KO. (2017): Intraoperative ketamine for prevention of postoperative delirium or pain after major surgery in older adults: an international, multicentre, double-blind, randomised clinical trial. Lancet, 390:267-75.

3. Bazin V,Bollot J, Asehnoune K, Roquilly A and Guillaud C. (2010): Effects of perioperative intraoperative low dose of ketamine on post-operative analgesia in children. Eur J Anesthiol., 27 (1): 47-52.

4. Bilotta F, Lauretta MP and Borozdina A. (2013): Postoperative delirium: risk factors, diagnosis and perioperative care. Minerva Aneshtesiol., 79(4):1066-76.

5. De Rooij SE and van Munster BC. (2013): Melatonin deficiency hypothesis in delirium: a synthesis of current evidence. Rejuvenation Research, 16(4):273-8.

6. Esmaoglu A, Yegenoglu F, Akin A, Aynur T, and Cemil Y. (2010): Dexmedetomidine added to Levobupivacaine prolongs axillary brachial plexus block.Anesthesia \& Analgesia 111 (6): 1548-51.

7. Gleason LJ, Schmitt EM, Kosar CM, Tabloski P, Saczynski JS and Robinson T. (2015): Effect of delirium and other major complications on outcomes after elective surgery in older adults. JAMA, Surg., 150:1134-40. 
8. Gupta K, Gupta A, Gupta PK, Rastogi B, Agarwal $S$ and Lakhanpal M. (2011): Dexmedetomidine premedication in relevance to ketamine anesthesia: A prospective study. Anesthesia, essays and researches, 5(1):87-94.

9. Hirsch J, Depalma G, Tsai T, Sands LP and Leung JM. (2015): Impact of intraoperative hypotension and blood pressure fluctuation on early postoperative delirium after non cardiac surgery BJA, 115 (3):418-26.

10. Hao P, Chengxiao J, Xiaochun L, Yanbing $M$, Mengyuan $Z$ and Yan W. (2019): Canadian Anesthesiologists' Society 2019. Can J Anesth/J Can Anesth., 66:1489-1500.

11. Inouye SK, Westendorp RG and Saczynski JS. (2014): Delirium in elderly people. Lancet, 383:911-22.

12. Lee HB and Park FG. (2010): Predisposing factors for post-operative delirium after hip fracture repair in individuals with and without dementia. JAM Geriatr Soc., 59 (4):2306-13.

13. Maldonado JR. (2013): Neuropathogenesis of delirium: review of current etiologic theories and common pathways. Am J Geriatr Psychiatry, 21(12):1190-222.

14. Mei B, Meng G, Xu G, Cheng X, Chen S, Zhang $Y$, Zhang $M$, Liu $X$ and Gu E. (2018): Intraoperative sedation with dexmedetomidine is superior to propofol for elderly patients undergoing hip arthroplasty. The Clinical Journal of Pain, 34(9):811-7.

15. Mizrak A, Erbagci I and Arici T. (2010): Ketamine versus propofol for strabismus surgery in children. Clin Ophthalmol., 4: 6739.

16. Pan Z, Huang K, Huang W, Kim KH, Wu H, Yu Y, Kim KN, Yi S, Shin DA, Vora D,
Gragnaniello C, Phan K, Tasiou A, Winder MJ, Koga H, Azimi P, Kang SY and Ha Y. (2019): written on behalf of the AME Spine Surgery Collaborative Group. The risk factors associated with delirium after lumbar spine surgery in elderly patients. Quant Imaging Med Surg., 9(4):700-710.

17. Rudolph JL, Inouye SK, Jones RN, Yang FM, Fong TG and Levkoff SE. (2010): Delirium: an independent predictor of functional decline after cardiac surgery. J Am Geriatr Soc., 58(4):643-8.

18. Sieber FE, Zakariya KJ and Gottschalk A. (2010): Sedation depth during spinal anesthesia and the development of postoperative delirium in elderly patients undergoing hip fracture repair. Mayo Clin Proc., 85:18-26.

19. Su X, Meng ZT, Wu XH, Cui F, Li HL, Wang DX, Zhu X, Zhu SN, Maze $M$ and Ma D. (2016): Dexmedetomidine for prevention of delirium in elderly patients after non-cardiac surgery: arandomised, double-blind, placebo-controlled trial. Lancet, 388:1893-902.

20. Xudong Y, Zhenzhen L, Chunyan G, and Ruichang M. (2015): American Association of Oral and Maxillofacial Surgeons J Oral Maxillofac Surg., 73:1065-1072.

21. Zhang H, Lu Y, Liu M, Zou Z, Wang L, Xu FY and Shi XY. (2013): Strategies for prevention of postoperative delirium: a systematic review and meta-analysis of randomized trials. Critical Care, 17(2):47-55. 
دراسة تأثير عقار الديكسميديتوميدين وعقار البرويوفول وعقار

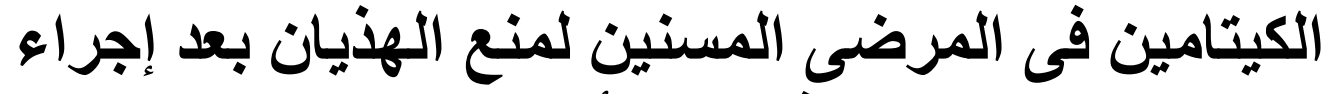

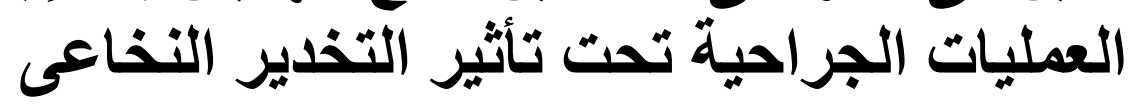

\section{يسرى محمد عبد السلام قنديل}

قسم التخدير والعناية المركزة بطب الأزهر (دمياط)

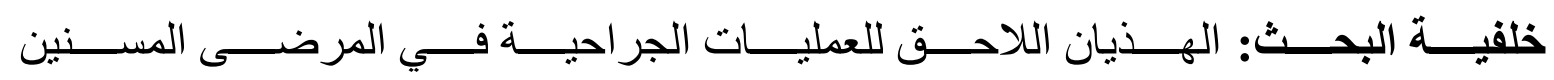

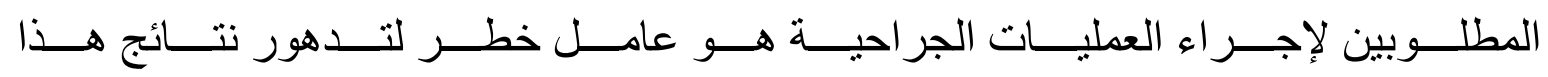

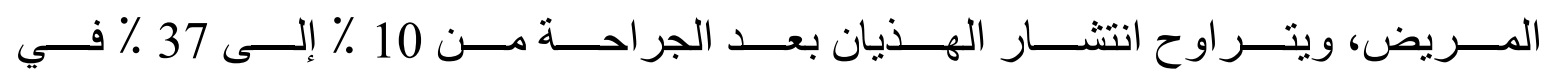

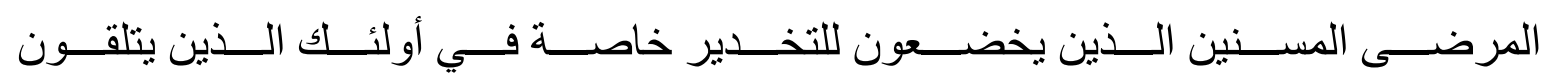

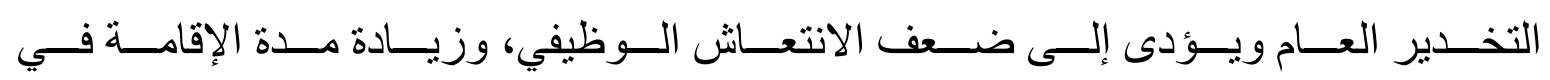

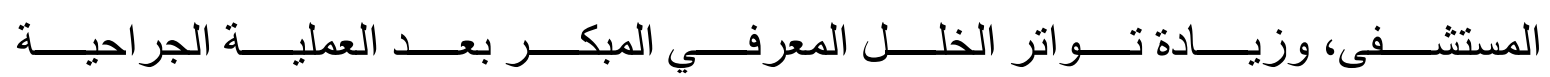

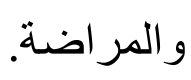

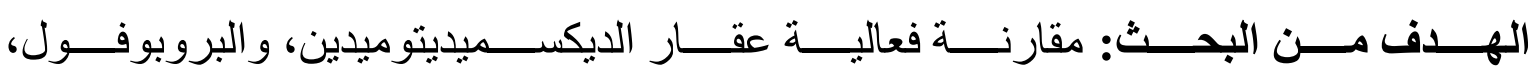

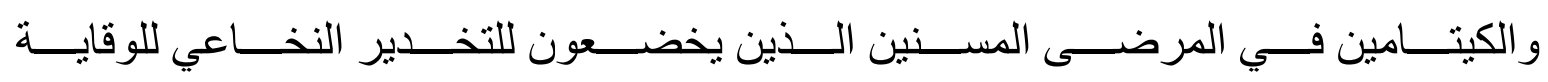
من الهذيان بعد الجر احة.

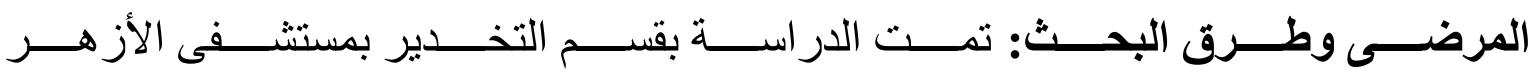

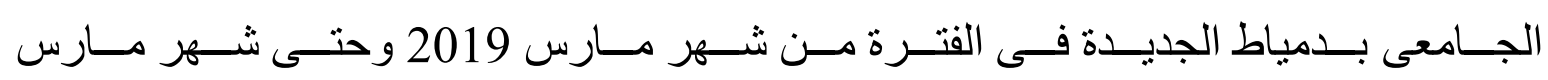

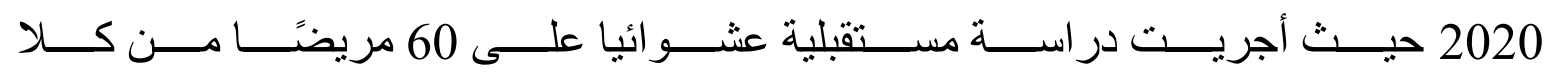

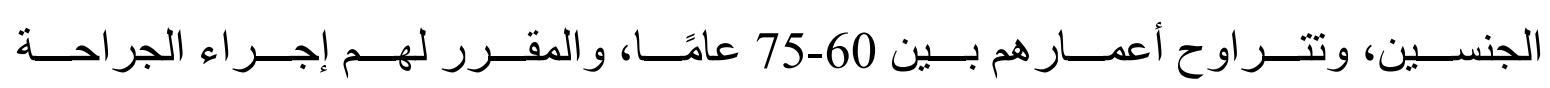

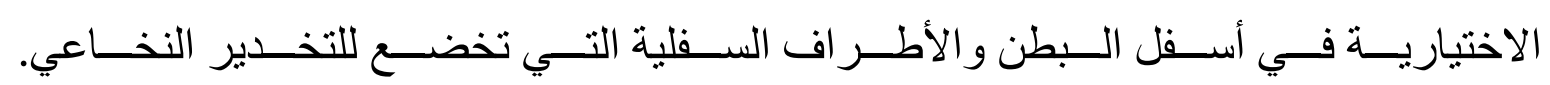
وقد نم اختيار هم عشو ائياً في ثلاث مجمو عات منساوية:

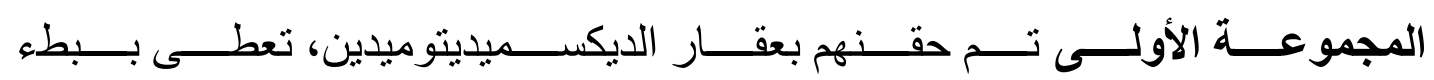

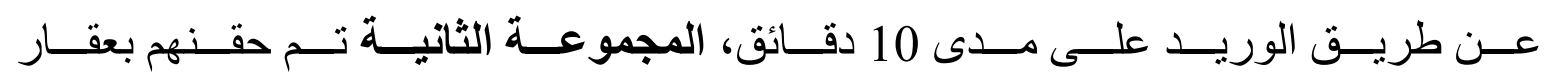

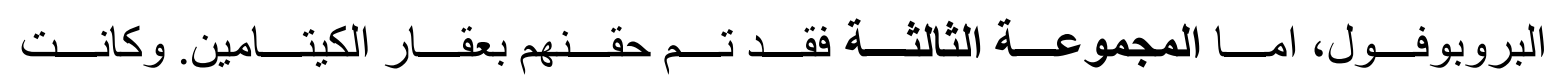




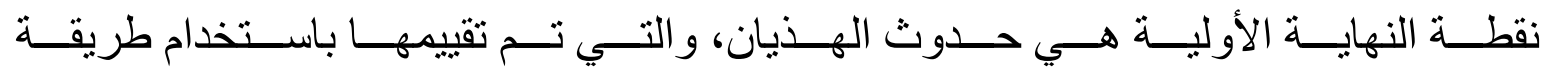
تقييم الارتباك من اليوم الأول بعد الجر احة إلى اليوم الثالث بعد الجر احة.

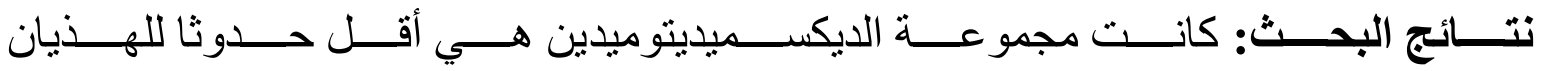

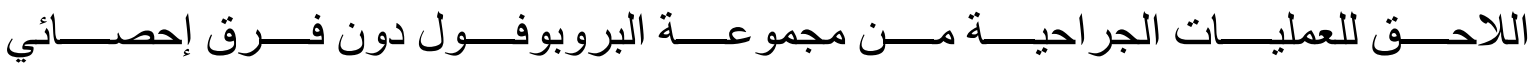

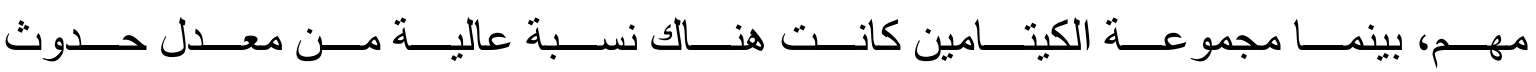
الهذيان مع فرق إحصائي من المجمو عتين الاخريتين.

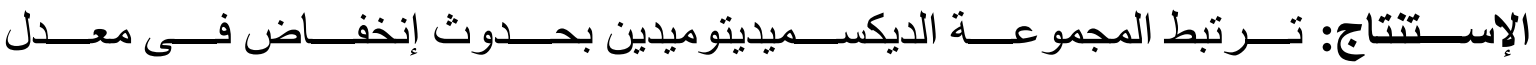

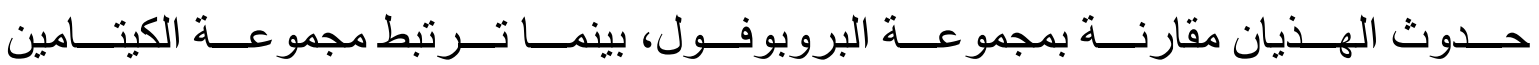

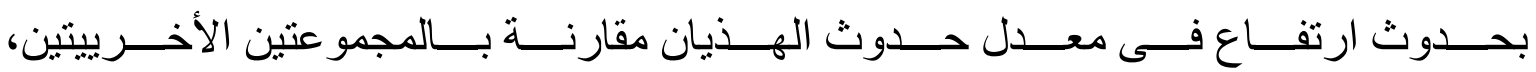

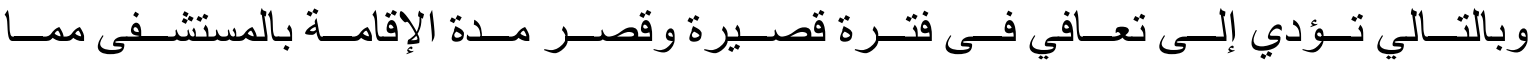
يؤدى إلى تقليل تكلفة الرعاية الصحية. 